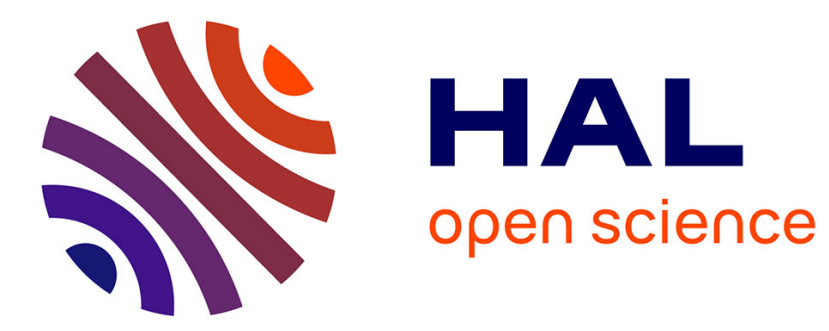

\title{
Enhanced Field Emission from Diamond Coated Molybdenum Emitters
}

\author{
W. Choi, M. Mcclure, R. Schlesser, Z. Sitar, J. Hren
}

\section{To cite this version:}

W. Choi, M. Mcclure, R. Schlesser, Z. Sitar, J. Hren. Enhanced Field Emission from Diamond Coated Molybdenum Emitters. Journal de Physique IV Proceedings, 1996, 06 (C5), pp.C5-97-C5-102. 10.1051/jp4:1996515 . jpa-00254394

\section{HAL Id: jpa-00254394 https://hal.science/jpa-00254394}

Submitted on 1 Jan 1996

HAL is a multi-disciplinary open access archive for the deposit and dissemination of scientific research documents, whether they are published or not. The documents may come from teaching and research institutions in France or abroad, or from public or private research centers.
L'archive ouverte pluridisciplinaire HAL, est destinée au dépôt et à la diffusion de documents scientifiques de niveau recherche, publiés ou non, émanant des établissements d'enseignement et de recherche français ou étrangers, des laboratoires publics ou privés. 


\title{
Enhanced Field Emission from Diamond Coated Molybdenum Emitters
}

\author{
W.B. Choi, M.T. McClure, R. Schlesser, Z. Sitar and J.J. Hren \\ Department of Materials Science \& Engineering, North Carolina State University, Raleigh, \\ NC 27695-7907, U.S.A.
}

\begin{abstract}
The field emission characteristics of individual Mo emitters were measured before and after diamond deposition, as well as before and after annealing. After coating without annealing, the emission current increased dramatically. Subsequent annealing resulted in further increases in emission and improved current stability. After coating, the energy distribution of the emitted electrons was found to shift with applied field. Annealing reduced the peak shift but resulted in the appearance of a second peak, coincident with the formation of $\mathrm{Mo}_{2} \mathrm{C}$ at the diamond-molybdenum interface. These changes in the emission spectra in conjunction with I-V data are discussed in terms of possible changes in emission mechanism.
\end{abstract}

\section{INTRODUCTION}

A number of investigators have reported that coating silicon and metal substrates with several types of diamond have led to significant improvements in field electron emission [1 5]. We have found that Mo emitters coated with diamond powders deposited by dielectrophoresis give enhancement in emission comparable to other methods [6]. The emission current was found to increase by more than an order of magnitude compared with the same uncoated emitter. Several possible mechanisms for this improvement have been suggested. Zhirnov et al. [4] suggested that emission from protrusions on the diamond surfaces enhances the local field strength. Huang et al. [8] suggest that electrons originated from a subband in the energy gap of the diamond. Geis et al. [3] proposed that a roughened metal substrate enhances the local field at the diamondmetal interface. $\mathrm{Xu}$ et al. suggested that electrons are transferred through graphitic channels within the diamond. Latham [7] proposed a MIV (Metal-Insulator-Vacuum) model for insulators in which he assumed a high defect density and high doping levels from impurities. He suggested that electrons could then tunnel into the conduction band of the insulator through a thin depletion layer and subsequently be heated by the penetrating electric field and transported through the barrier at the insulator-vacuum surface.

Even if the diamond/vacuum surface has a negative electron affinity, the diamond/metal interface remains a barrier to electron transport. Clearly it is essential to reduce the interfacial barrier if one is to achieve high electron emissivity. Two methods can be considered: minimizing the width of the depletion layer using highly doped diamond and/or introducing defects at the metal interface e.g by forming an interfacial carbide. No true n-type doping of diamond has yet been reported, but carbide-forming metals such as Mo, Ti, and $\mathrm{Ta}$ have been used as substrates for diamond coatings. Moazed et al. [10] reported an ohmic contact on Mo/p-type diamond after annealing. Tachibana et al. [11] and Gildenblat et al. [12] also suggest that formation of titanium 
carbide may alter the Schottky barrier to ohmic contact with diamond.

Our earlier results showed that diamond powders deposited onto Mo and Si emitters, even without annealing, enhance electron emissivity substantially, suggesting that the barrier to electron tunneling can be reduced by formation of a physical interface alone. This result can be explained if one includes the effective mass of the electrons in the conduction band of diamond and the diamond is nitrogen doped $[2,9]$. However, it is clearly better to achieve a more permanent bond between the diamond particles and the Mo emitter, for example, by annealing the specimens. There are two main aims: no shape change of the Mo and the formation of a chemical bond. TEM results showed that $\mathrm{Mo}_{2} \mathrm{C}$ carbide formed on the diamond/Mo interface at annealing temperatures as low as $\sim 430^{\circ} \mathrm{C}[13,14]$. The results presented here relate the current-voltage (IV) characteristics and the field emission energy distribution from the same Mo field emitters before and after diamond coating, and then after heat treatment. In turn these data suggest a plausible mechanism for the enhanced emission.

\section{EXPERIMENTAL PROCEDURE}

Mo emitters (with radii $60 \mathrm{~nm}$ or smaller) were fabricated from $0.125 \mathrm{~mm}$ wire by electrochemical etching in a concentrated $\mathrm{KOH}$ solution at $10 \mathrm{~V}$ dc. After suitable cleaning, I-V characterization was conducted on pure Mo emitters. Then the emitters were coated with HPHT (High pressure, High temperature) diamond powder using dielectrophoresis [6]. I-V characterization was repeated after coating, and again after annealing on the same specimen for direct comparison. The diamond coated emitters were annealed for times up to $30 \mathrm{~min}$. and temperatures as high as $600^{\circ} \mathrm{C}$ in a partial pressure of 100 Torr hydrogen. All emission measurements were carried out at $1^{*} 10^{-9}$ Torr vacuum and at room temperature with a tip-to-anode distance of $10 \mathrm{~mm}$ [2]. The morphology of the diamond coatings was determined by a scanning electron microscope. The electron energy distribution was obtained using a suitable applied voltage $(200-700 \mathrm{~V})$ between the holder and an extraction gate with a $500 \mu \mathrm{m}$ opening and a tip-to-gate distance of $400 \mu \mathrm{m}$. This holder was positioned at the entrance slit to a CLAMII (Vacuum Generators Ltd.) hemispherical electron energy analyzer . Typical data collection conditions included a dwell time of $100 \mathrm{~ms}$, an energy step of $0.025 \mathrm{eV}$. Three scans taken over each desired energy range. Before all measurements, a thermal desorption treatment was performed at $\sim 400^{\circ} \mathrm{C}$ for one hour.

\section{RESULTS AND DISCUSSION}

\section{I I-V characterization}

The field emission characteristics of the Mo emitters were investigated before and after diamond deposition, and then after annealing. Fig. 1 shows the I-V characterization of a Mo tip with a $150 \mathrm{~nm}$ tip radius coated with a thin $(\sim 100 \mathrm{~nm})$ coating of diamond particles. After coating the electron emissivity was found to increase in a manner comparable to the data presented earlier[1, $2,6]$. The improved emission was attributed to a reduction in the "effective workfunction", i.e. a lower overall barrier to emission as a consequence of coating alone with no measurable change in the shape of the Mo tip [2,9]. Further annealing increased the electron emissivity an additional 
two orders of magnitude compared with the unannealed diamond coated tip. The tip morphology was not measurably changed by such annealing as deduced from electron microscopy (Fig. 2). It was also observed by High Resolution Transmission Electron Microscopy that $\mathrm{Mo}_{2} \mathrm{C}$ regions were formed at the diamond-molybdenum interface during annealing [13,14]. Other investigators $[10,11,12]$ have suggested that carbide formation between diamond and transition metals may lower the Schottky barrier and even develop an ohmic contact. We suggest that these carbides may reduce the energy barrier between Mo and the conduction band of diamond.

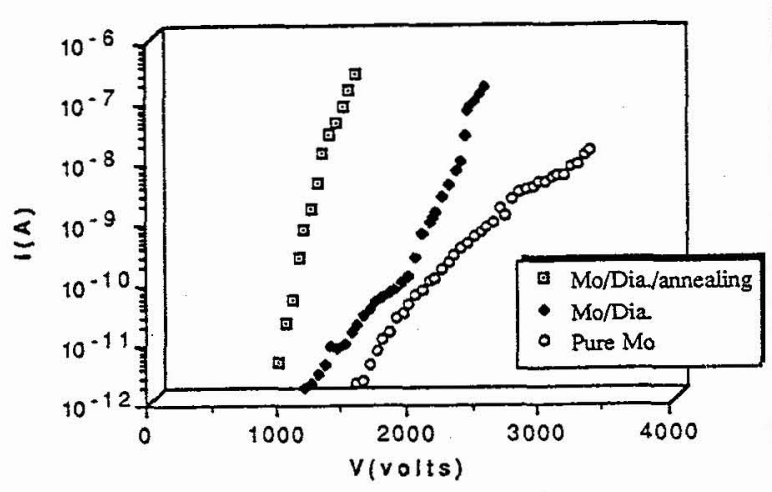

Fig. 1 Field emission characteristics of Mo field emitter before and after diamond coating, and after annealing.

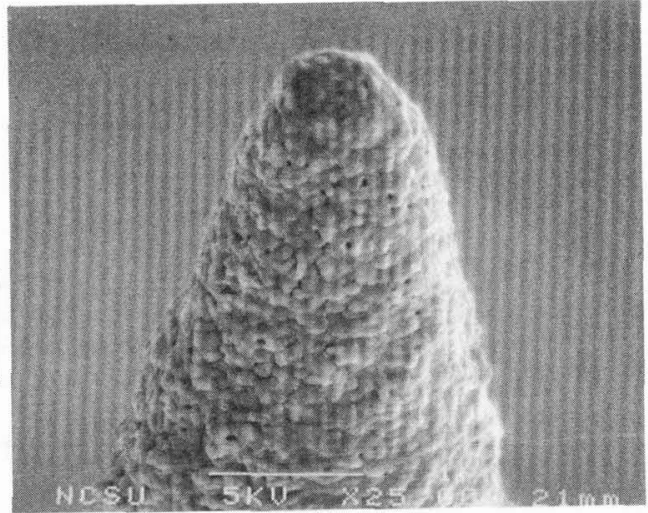

Fig. 2 SEM micrograph of diamond coated Mo field emitter after annealing.

\subsection{Energy distribution}

Fig. 3 shows the results of energy distribution analysis from a pure Mo tip, after diamond coating, and after annealing treatment. The three emitter conditions gave widely different intensities, varying by over $10^{3}$ times at the same voltage $\left(\mathrm{Vo}_{0}=450\right.$ volts $)$ and their maxima are displaced one from another when plotted as a function of the applied bias. The dependence of this peak displacement with applied voltage is plotted in Figure 4 and shows strikingly differing behavior depending upon emitter condition. The peak shift of the energy spectrum maxima with respect to the Mo Fermi energy level for the diamond coated tip and annealed tip increased with the applied voltage while that of the Mo tip remained constant (Fig. 4). This peak shift represents the internal voltage drop which is comprised of the difference between the Fermi level in the metal substrate and the effective Fermi level at the emitting surface. This is consistent with the constant value of $4.5 \mathrm{eV}$ obtained as a function of a $\mathrm{V}_{0}$ for pure $\mathrm{Mo}$ in (Figure 4). After diamond coating, the shift of the energy distribution maximum increased up to $7 \mathrm{eV}$ from that of pure Mo at 625 applied volts. It is proposed that the peak shift in the diamond coated Mo tip is related to the condition of the metal/diamond contact and to the diamond bulk voltage drop (Fig. 5). However after annealing, the magnitude of the peak shift was considerably reduced. The annealing reduces the total voltage drop because the $\mathrm{Mo} /$ diamond barrier is reduced through formation of $\mathrm{Mo}_{2} \mathrm{C}$ at this interface. 


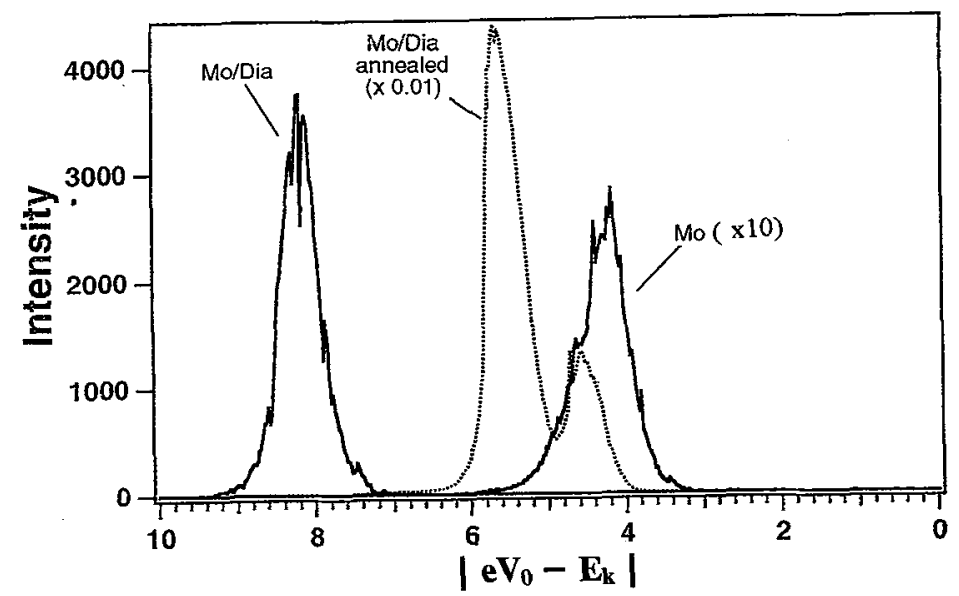

Fig. 3 The field emission energy spectrum at applied voltage of $450 \mathrm{~V}$ for Mo, Mo/Diamond and annealed Mo/Diamond emitter. The spectrum from annealed emitter shows 100 times reduction and pure Mo shows 10 times enlargement from its real size. ( unit of $\mathrm{x}$-axis is $\mathrm{eV}, \mathrm{e}=\mathrm{electron}$ charge, $V_{0}=$ applied bias, $E_{k}=$ kinetic energy of electrons emitted from sample)

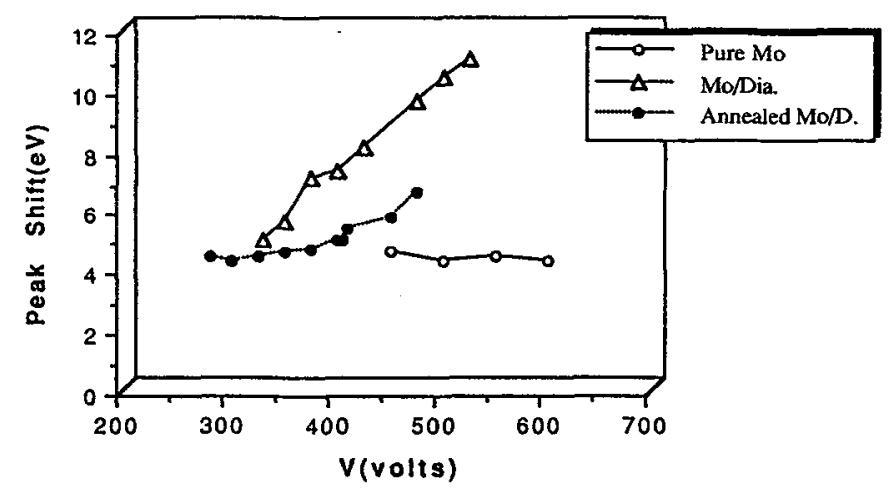

Fig. 4 The shift in position of the peak in the energy distribution is shown as a function of applied voltage for the same sample of different conditions.

A second peak at an energy higher than the original peak appeared after annealing, but not until the applied field reached a threshold value. The peak position was $1.1 \mathrm{eV}$ higher than that of the main peak, which may correlate with a lower work function for $\mathrm{Mo}_{2} \mathrm{C}$ compared with Mo. Our previous TEM results had already confirmed that $\mathrm{Mo}_{2} \mathrm{C}$ formed during annealing. [13,14]. Tumareva [15] and Athwal et al. [16] suggest that such a high energy second peak is related to the second-valley of the conduction band. Whether this peak is due to local formation of a carbide or due to the electron structure of the diamond or a second emission site is unclear and 
further study is required.

Several different mechanisms for the improvement of field emission from diamond coated field emitters have been proposed. No single mechanism alone seems capable of explaining the field emission data before and after diamond coating followed by annealing. We suggest that the emission mechanisms changed after annealing and that these changes are associated with the interface microstructure. The enhanced emission after diamond coating alone can be explained by the field penetration model [2,9], which relies upon reduction of the effective barrier at the metal/diamond interface especially if the effective mass of electrons in the diamond conduction band and nitrogen doping is taken into account. After annealing, the Schottky barrier of the Mo /diamond interface can be reduced by carbide formation and by defects generated near the diamond surface, as Tachibana et al. [11] suggest. These local defects should narrow the depletion width and increase the electron tunneling probability. The interfacial barrier can be reduced even further by simply making a better contact as a consequence of annealing (note: The resistivity of $\mathrm{Mo}_{2} \mathrm{C}$ is similar to that of the $\mathrm{Mo}$ ). In addition, carbides formed at the interface may yield local field enhancement, which is in turn consistent with the appearance of a second peak at a threshold value and with a peak shift (figure 4). Therefore electrons tunneling through the narrowed depletion region into the conduction band of the diamond can be transported through the diamond and emitted at the diamond surface into vacuum. Latham et al. [7] have suggested a similar model to explain electron transport through dielectrics under the assumption of a high density of donors. Carbide formation may also provide a narrower depletion layer even in intrinsic diamond through the creation of defects near the interface. Both the high emissivity and lowered voltage drop can be explained by the proposed changes in emission mechanism accompanying annealing. The details of this model are now undergoing rigorous experimental tests.

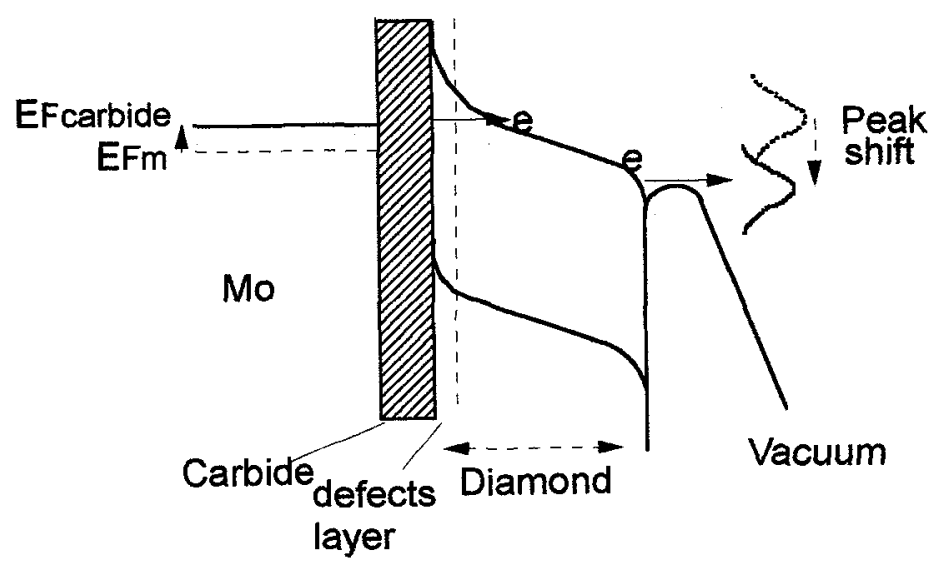

Fig. 5 The band diagram of annealed diamond coated Mo field emitter. The reduction of the Schottky barrier height is shown after carbide formation and the width of the depletion layer decreased in considering defects generation. (Efm: metal workfunction, Efc: carbide workfunction) 


\section{Acknowledgements}

The authors wish to thank Prof. J.J. Cuomo for his support during this work. We appreciate A.F. Myers, V.V. Zhirnov and G.J.Wojak for useful discussion.

\section{References.}

[1] V.V. Zhirnov, W.B. Choi, J.J. Cuomo and J.J. Hren, Appl. Surf. Sci. 94/95, (1996) 123.

[2] W.B. Choi, J. Liu, M.T. McClure, V.V. Zhirnov, A.F. Myers, J.J. Cuomo and J.J. Hren, presented at the 8th IVMC '95, OR. 1995 ( J. Vac. Sci. Technol. B May/June, (1996) 2050.

[3] M.W. Geis, J.C. Twichell, N.N. Efremow, K. Krohn, and T.M. Lyszczarz, Appl. Phys. Lett. 68, (1996) 2294.

[4] E.I. Givargizov, V.V. Zhirnov, A.N. Stepanova, E.V. Rakova, A.N. Kiselev, and P.S. Plekhanov, Appl. Surf. Sci. 87/88 (1995) 24.

[5] K. Okano, S. Koizumi, S. Ravi, P.Silva and G.A.J. Amaratunga, Nature vol. 381, (1996) 140. [6] W.B. Choi, J.J. Cuomo, V.V. Zhirnov, A.F. Myers, and J.J. Hren, Appl. Phys. Lett. 68, (1996) 720.

[7] R.V. Latham, 'High voltage vacuum insulation' Academic Press, 1995 pp128.

[8] Z.H. Huang, P.H. Cutler, N.M. Miskovsky, and T.E. Sullivan, J. Vac. Sci. Technol. B 13, (1995) 526.

[9] V.V. Zhirnov, R.J. Nemanich, W.B. Choi and J.J. Hren, (in preparation).

[10] K.L. Moazed, J.R. Zeidler, and M.J. Taylor, J. Appl. Phys. 68, (1990) 2246.

[11] T. Tachibana, B.E. Williams, and J.T. Glass, Phys. Rev. B 45, (1992) 11975.

[12] G.Sh. Gildenblat, S.A. Grot, C.W. Hatfield, A.R. Badzian and T. Badzian, IEEE Electron Device Lett., 11, (1990) 371.

[13] W.B. Choi, A.F. Myers, G.J. Wojak, M.T. McClure, J.J. Cuomo and J.J. Hren, presented at the 9th IVMC '96, St. Petersburg, Russia. (Technical digest pp. 288 - 292)

[14] A.F.Myers, Characterization of diamond coated silicon and molybdenum field emitters, Ph.D. Thesis, North Carolina State University (1996).

[15] C.S. Athwal and R.V. Latham, J. Phys. D: Appl. Phys.,17 (1984) 1029.

[16] T.A. Tumareva, V.A. Ivanov, T.S. Kirsannova, Appl. Surf. Sci. 87/88, (1995) 18. 